\title{
MENINGKATKAN PRODUKTIVITAS KARYAWAN MELALUI PEMBERDAYAAN, KERJA SAMA TIM DAN PELATIHAN DI PERUSAHAAN JASA
}

\author{
I Made Adi Prabawa ${ }^{1}$ \\ I Wayan Gede Supartha ${ }^{2}$ \\ ${ }^{12}$ Fakultas Ekonomi dan Bisnis Universitas Udayana (UNUD), Bali, Indonesia \\ email: adiprabawamd@yahoo.com
}

\begin{abstract}
ABSTRAK
Meningkatnya produktivitas karyawan dapat memberikan keunggulan kompetitif bagi sebuah perusahaan. Penelitian bertujuan untuk mengetahui pengaruh pemberdayaan, kerja sama tim dan pelatihan terhadap produktivitas karyawan. Penelitian dilakukan di Unagi Spa Bali. Total 40 orang karyawan dijadikan sampel. Data dikumpulkan lewat kuesioner kemudian diukur dengan skor skala Likert. Regresi Linear Berganda digunakan untuk menganalisis data. Temuan penelitian ini adalah variabel pemberdayaan, kerja sama tim dan pelatihan masing-masing berpengaruh positif sekaligus signifikan terhadap produktivitas karyawan di Unagi Spa Bali. Pemberdayaan secara luas telah diakui sebagai kontributor kunci keberhasilan dalam memaksimalkan produktivitas. Menerapkan kerja sama tim juga merupakan hal utama dari manajemen sukses yang bertujuan untuk meningkatkan hasil secara keseluruhan dalam hal produktivitas. Produktivitas karyawan menjadi lebih efisien jika menerima pelatihan yang efektif.
\end{abstract}

Kata kunci: pemberdayaan, kerja sama tim, pelatihan dan produktivitas karyawan.

\begin{abstract}
An increased productivity provides a competitive advantage for a company. This research aim to understand the impact of empowerment, teamwork, and training on workforce productivity. The research takes place in Unagi Spa Bali, and 40 employees participate as sample. Data were collected by questionnaire then measured using Likert scale score. Multiple Linear Regression is used to analyze. The result indicates that each variable empowerment, teamwork and training partially has a positive and significant impact on workforce productivity at Unagi Spa Bali. Empowerment is considered as one of key to success in maximizing productivity. Teamwork is also key feature of successful management aimed to improve overall outcomes of productivity. An effective training helps to create an efficient workforce productivity.
\end{abstract}

Keywords: empowerment, teamwork, training and employee productivity. 
I Made Adi Prabawa, Meningkatkan Produktivitas Karyawan Melalui...

\section{PENDAHULUAN}

Upaya meningkatkan produktivitas suatu perusahaan bukanlah dengan cara bekerja lebih keras, tetapi bekerja lebih cerdas (Widodo, 2015:217). Keberhasilan suatu perusahaan atau organisasi dalam meningkatkan produktivitas akan sangat mendukung kemampuan bersaingnya. Tuntutan kompetensi di tengah kompetisi pada akhirnya akan menjadi hal yang tidak boleh diabaikan. Berbagai faktor dapat mempengaruhi produktivitas misalnya dari SDM itu sendiri maupun dari luar seperti lingkungan kerja, sarana produksi, dan kesehatan (Sutrisno, 2009:102). Polyzos (2005) menyebutkan bahwa produktivitas karyawan dalam perusahaan juga tergantung pada keefektifan kerjasama antara individu dan kelompok. SDM merupakan elemen yang paling strategis dalam organisasi dalam hal mencapai produktivitas yang tinggi. Unagi Spa Bali adalah salah satu perusahaan yang berada di Kota Denpasar yang bergerak dalam bidang industri Spa.

Faktor-faktor pendukung telah diterapkan perusahaan untuk mencapai keberhasilan usahanya seperti melakukan promosi, memperbaiki manajemen, mengadakan kerjasama bisnis, serta menjaga dan meningkatkan kualitas layanan. Agar dapat memberikan pelayanan terbaiknya, tentu diperlukan produktivitas karyawan yang tinggi. Perusahaan harus menuntut diri agar mampu menjaga dan meningkatkan produktivitas karyawannya melalui manajemen SDM yang efektif dan efisien. Unagi Spa Bali yang bergerak pada pelayanan jasa memiliki target "To be The Local Champion, within a year" yang dibuktikan dengan adanya target jumlah kunjungan pelanggan. Data target dan capaian jumlah kunjungan dari pelanggan yang melakukan perawatan adalah sebagai berikut: 
Tabel 1. Data Jumlah Target dan Capaian Perawatan Unagi Spa Bali Tahun 2017

\begin{tabular}{lcc}
\hline Periode & Target bulanan (pax) & Capaian (pax) \\
\hline Januari & 750 & 682 \\
Februari & 750 & 756 \\
Maret & 750 & 700 \\
April & 750 & 947
\end{tabular}

Sumber: Unagi Spa Bali, 2017

Berdasarkan Tabel 1, diketahui bahwa pada bulan Februari dan April jumlah perawatan sudah mencapai dan melebihi target. Pada bulan Januari dan Maret target tersebut belum tercapai. Produktivitas karyawan merupakan hal penting yang harus dipehatikan agar nantinya jumlah perawatan diharapkan mampu meningkat dan mencapai target pada bulan-bulan berikutnya, karena produktivitas merupakan hubungan kualitas yang dihasilkan dengan banyaknya pekerjaan yang dilakukan untuk mencapai hasil kerja (Chen, 2000).

Kien (2012) menyatakan bahwa produktivitas merupakan faktor penting untuk membangun daya saing organisasi, mempertahankan kinerja strategis dan keuangan, mencapai tujuan yang diinginkan dan memenuhi proposi nilai pemangku kepentingan. Vrat et al., (2009) menyebutkan untuk mencapai produktivitas karyawan yang maksimal diperlukan adanya manajemen yang efektif. Ukuran pencapaian produktivitas karyawan yang maksimal tidak hanya ditentukan dengan sejumlah angka, melainkan pada sejumlah output yang diperoleh dari seseorang karyawan selama periode waktu yang telah ditetapkan (Mokhtar et al., 2010).

Selain indikasi rendahnya produktivitas, hasil wawancara terhadap 7 orang Karyawan di Unagi Spa Bali menunjukan permasalahan seperti karyawan merasa kurang diberdayakan, masih rendahnya kerja sama tim dan pelatihan yang kurang 
I Made Adi Prabawa, Meningkatkan Produktivitas Karyawan Melalui...

efektif. Hanaysha (2016) menyatakan bahwa faktor perilaku seperti pemberdayaan, kerja sama tim, serta pelatihan melaporkan arah positif sekaligus signifikan terhadap produktivitas karyawan di perusahaan jasa khususnya sektor perguruan tinggi.

Indikasi kurangnya pemberdayaan, karyawan merasa tidak memiliki kompetensi yang memadai dalam melaksanakan tugas yang dipercayakan kepadanya dan tidak memiliki kebebasan dalam mengerjakan tugas-tugas yang diberikan. Seperti jika akan menghandle pelanggan asing beberapa karyawan masih ragu untuk melayani dan berupaya untuk menukar tugas kepada karyawan lainnya. Disamping itu setiap pekerjaan yang ditugaskan kepada karyawan masih harus diarahkan dan dinilai kurang inisiatif oleh atasan. Pernyataan lain menunjukan, jika ada pelanggan yang ingin menggabungkan atau meminta paket perawatan khusus, therapist harus meminta persetujuan atasan terlebih dahulu dimana hal ini membuat pekerjaan tertunda dan tidak dapat diselesaikan dengan cepat. Pemberdayaan karyawan merupakan strategi penting bagi organisasi untuk meningkatkan kekuatan dan keterlibatan karyawan mereka dengan asumsi bahwa karyawan yang diberdayakan cenderung lebih efisien dalam menyelesaikan pekerjaan mereka (Saifullah et al., 2015).

Benrazavi dan Silong (2013) menyatakan kerja sama tim sebagai faktor penting yang memberikan kontribusi terhadap produktivitas karyawan. Kerja sama tim merupakan kegiatan bersama yang bertujuan untuk mencapai tujuan bersama dengan melibatkan anggota organisasi dalam kelompok tertentu untuk berbagi pengetahuan dan keterampilan mereka satu sama lain (Seppala, 2015). 
Rendahnya kerja sama tim di Unagi Spa Bali paling dirasakan pada departemen Therapist. Hal tersebut dibuktikan dengan perilaku Therapist yang memilih-milih teman kerja untuk menghandle pelanggan, sehingga terdapat indikasi adanya kelompok di dalam kelompok kerja. Hal ini menandakan kerja sama tim belum optimal walaupun telah diterapkan oleh perusahaan. Karyawan juga sering menukar jadwal yang telah dibuat Front Office secara mendadak, sehingga tidak ada karyawan pengganti dan akibatnya terjadi kekurangan Therapist pada saatsaat tertentu.

Penelitian yang dilakukan Athar (2015) melaporkan pelatihan memiliki pengaruh positif serta signifikan terhadap produktivitas. Singh (2012) menyatakan pelatihan adalah proses yang berkelanjutan melalui mana karyawan yang benarbenar memperoleh pengetahuan yang diperlukan dan dapat mengetahui bagaimana melakukan pekerjaan dengan baik. Unagi Spa Bali telah menyediakan pelatihan di dalam departemen, antar departemen atau unit dan di luar perusahaan baik untuk karyawan baru dan lama diantaranya: Grooming Training, Product Knowledge Training, dan Pelatihan mengenai Tata Tertib dan Peraturan Perusahaan. Namun realisasi pelatihan tersebut belum optimal dikarenakan manajemen kesulitan dalam mengatur jadwal pelatihan dan mengumpulkan staff, mengingat operasional perusahaan juga harus tetap berjalan. Disamping itu jam operasional perusahaan yang dimulai dari jam $08.00-23.00$ Wita setiap harinya juga menjadi kendala untuk memberikan pelatihan di luar jam kerja karyawan. Hanif dan Abdullah (2013) menyatakan bahwa sebuah organisasi yang mampu untuk merancang suatu lingkungan yang menekankan pada pelatihan dapat dinilai 
I Made Adi Prabawa, Meningkatkan Produktivitas Karyawan Melalui...

dengan adanya karyawan yang memiliki kesempatan yang lebih baik untuk mendapatkan komitmen yang lebih besar.

Hasil ini diharapkan dapat menambah penelitian empiris dengan membuktikan pengaruh pemberdayaan, kerja sama tim, dan pelatihan terhadap produktivitas karyawan khususnya di perusahaan jasa. Perusahaan jasa dipilih untuk melakukan penelitian ini karena industri Spa di Bali yang semakin berkembang dinilai harus mampu bersaing dan memiliki keunggulan kompetitif.

Sultana et al., (2012) menggambarkan produktivitas sebagai kemampuan untuk mencapai tugas-tugas tertentu sesuai dengan standar yang ditetapkan seperti ketepatan, kelengkapan, biaya-biaya, dan lamanya kerja. Artinya, produktivitas karyawan dapat dinilai dari segi efisiensi karyawan dalam melakukan tugastugasnya. Sejumlah definisi untuk produktivitas karyawan dikemukakan dalam sejumlah penelitian, seperti Ferreira dan Du Plessis (2009) menyatakan produktivitas adalah waktu habis guna untuk menyelesaikan tugas-tugasnya dalam bekerja, dalam rangka mencapai hasil yang diharapkan berdasarkan deskripsi pekerjaan. Kien (2012) menunjukkan bahwa meningkatnya produktivitas karyawan dapat menyebabkan hasil yang menguntungkan seperti: keunggulan kompetitif, mempertahankan hasil strategis dan keuangan, serta mencapai tujuan organisasi.

Meyerson dan Dewettinck (2012) menyatakan pemberdayaan adalah proses menukar kekuasaan, otoritas dengan tanggung jawab, dan akuntabilitas kepada karyawan melalui manajer mereka. Akibatnya, karyawan dapat mengembangkan kompetensi untuk secara aktif melakukan tugas mereka dengan menerapkan 
pengetahuan dan keterampilan mereka (Jacquiline, 2014). Pemberdayaan karyawan dibangun dengan merancang lingkungan kerja dimana karyawan diizinkan untuk membuat keputusan mereka sendiri berdasarkan pekerjaan yang berhubungan dengan kondisi tertentu (Elnaga dan Imran, 2014). Pemberdayaan karyawan merupakan strategi penting yang digunakan oleh banyak organisasi untuk meningkatkan kekuatan dan keterlibatan karyawan mereka dengan asumsi bahwa karyawan yang diberdayakan cenderung lebih efisien dalam menyelesaikan pekerjaan mereka (Saifullah et al., 2015). Menurut Chang (2008), pemberdayaan mengarah ke hasil positif organisasi, seperti tanggung jawab dan motivasi dalam pekerjaan rutin ditingkat karyawan, meningkatkan kepuasan kerja, kualitas layanan yang lebih baik, loyalitas karyawan yang lebih tinggi, dan memaksimalkan produktivitas.

Karacoc (2009) menyebutkan dengan mengadopsi strategi pemberdayaan, diyakini bahwa karyawan akan merasakan diri mereka layak, dan berefek pada meningkatkan produktivitas serta kualitas pekerjaan. Chehrazi dan Shafizadeh (2016) menyatakan terdapat hubungan erat antara pemberdayaan karyawan dengan kepuasan kerja, sehingga meningkatkan produktivitas. Meyerson dan Dewettinck (2012) juga menemukan bahwa pemberdayaan memiliki efek positif yang signifikan terhadap produktivitas karyawan. Teori $\mathrm{Z}$ merupakan penekanan pada peran dan posisi karyawan dalam suatu perusahaan.

Teori $\mathrm{Z}$ ini relevan bagi pemberdayaan jika dipahami lebih jauh dari sifat dan tujuan pemberdayaan itu sendiri. Menurut Widodo (2015:209) Teori Z ini menekankan perlunya berbagai wewenang pengambilan keputusan dan perlunya 
I Made Adi Prabawa, Meningkatkan Produktivitas Karyawan Melalui...

mengurangi rintangan-rintangan akibat perbedaan status artifisial antar karyawan, anggota dan manajer, dan menekankan perlunya komunikasi yang lebih baik serta tanggungjawab pribadi yang lebih besar atas hasil kerja, juga pengakuan yang lebih besar atas konstribusi tiap individu kepada tim.

H1: Pemberdayaan berpengaruh positif dan signifikan terhadap produktivitas karyawan

Kerja sama tim dipandang sebagai tindakan karyawan untuk mencapai tujuan tertentu atau dengan menempatkan kepentingan masing-masing anggota untuk kepentingan kelompok secara keseluruhan (Tyson, 2014). Selain itu, bekerja dalam tim memungkinkan karyawan untuk merasa diberdayakan dan ini mendukung mereka untuk mengembangkan otonomi, yang merupakan sumber kepuasan kerja dan tingkat stres yang rendah (Heredero, 2015). Benrazavi dan Silong (2013) menyatakan kerja sama tim sebagai faktor penting yang memberikan kontribusi terhadap produktivitas karyawan. Kerja sama tim merupakan kegiatan bersama yang bertujuan untuk mencapai tujuan bersama dengan melibatkan anggota organisasi dalam kelompok tertentu untuk berbagi pengetahuan dan keterampilan mereka satu sama lain (Seppala, 2015). Manzoor et al., (2011) mengungkapkan bahwa dukungan dari manajemen tingkat atas dapat membantu karyawan untuk percaya diri dalam bekerja dengan orang lain, kemudian akibatnya adalah dapat meningkatkan produktivitas.

Beberapa peneliti menambahkan bahwa kerja sama tim memungkinkan orang untuk saling membantu bersama-sama, meningkatkan keterampilan masingmasing, dan memperoleh umpan balik positif tanpa konflik di antara mereka 
(Tyson, 2007). Akibatnya, anggota tim yang mendapatkan kesempatan untuk belajar dan menerapkan keterampilan baru akan memiliki sikap yang lebih menguntungkan terhadap kerja sama tim (Jiang, 2010). Mayoritas organisasi yang berfokus pada kerja sama tim dalam upaya untuk mencapai target, akan meningkatkan produktivitas.

Penelitian Cohen dan Bailey (2009) menemukan organisasi yang lebih menekankan pada kerja sama tim dapat menikmati hasil yang menguntungkan seperti meningkatkan kinerja karyawan, tingginya produktivitas dan perluasan keterampilan dalam menyelesaikan pekerjaan Gallie et al., (dalam Hanaysha, 2014) menegaskan bahwa kerja sama tim memperkaya produktivitas melalui peningkatan ruang lingkup pengetahuan, keterampilan, dan kemampuan karyawan berbagi dengan karyawan lainnya. Penelitian yang dikemukakan oleh Agarwal (2016) merekomendasikan untuk mengadopsi kerja sama tim dalam meningkatkan produktivitas organisasi.

H2: Kerja sama tim berpengaruh positif dan signifikan terhadap produktivitas karyawan

Chan (2010) menyebutkan jika pelatihan berupa pembelajaran yang tersedia berbentuk usaha-usaha rangka meningkatkan kinerja karyawan yang melihat dan dengan pekerjaan yang dikerjakannya saat ini. Caple (dalam Priansa, 2014) menyatakan bahwa pelatihan merupakan upaya yang sistematis dan terencana untuk mengubah atau mengembangkan pengetahuan, keterampilan dan sikap melalui pengalaman belajar dalam rangka meningkatkan efektivitas kinerja kegiatan atau berbagai kegiatan. Tujuan pelatihan dalam situasi kerja, adalah 
I Made Adi Prabawa, Meningkatkan Produktivitas Karyawan Melalui...

untuk memungkinkan seseorang karyawan memperoleh kemampuan agar dapat melakukan tugas atau pekerjaan secara memadai, dan menyadari potensi yang mereka miliki.

Penelitian Athar (2015) menyatakan pelatihan memiliki pengaruh positif dan signifikan terhadap produktivitas. Hanif dan Abdullah (2013) menyatakan bahwa sebuah organisasi yang mampu untuk merancang suatu lingkungan yang menekankan pada pelatihan dapat dinilai dengan adanya karyawan yang memiliki kesempatan yang lebih baik untuk mendapatkan komitmen yang lebih besar. Colombo dan Stanca (2008), melaporkan tentang pelatihan sebagai alat utama dan kuat untuk berhasil mencapai tujuan organisasi dan meningkatkan produktivitas karyawan. Menurut Appiah (2010), program pelatihan yang dirancang untuk memberikan manfaat yang lebih besar bagi karyawan dan organisasi itu sendiri, dengan melalui berbagi pengetahuan, keterampilan, dan kompetensi dapat meningkatan produktivitas karyawan. Sabir et al., (2014) menemukan bahwa pelatihan dapat memungkinkan karyawan untuk memaksimalkan tingkat produktivitas. Produktivitas karyawan menjadi lebih efisien jika menerima pelatihan yang efektif (Elnaga dan Imran, 2013). Asava (2013) juga menemukan bahwa pelatihan mengarah ke hasil yang positif yang signifikan melalui dimensi pengetahuan, sikap, keterampilan dan kapasitas terhadap produktivas.

H3: Pelatihan berpengaruh positif dan signifikan terhadap produktivitas karyawan Untuk memperjelas arah penelitian dalam menguji adanya pengaruh pemberdayaan, kerja sama tim dan pelatihan terhadap produktivitas karyawan. Maka model konseptual digambarkan seperti berikut: 
Gambar 1. Model Konseptual Penelitian

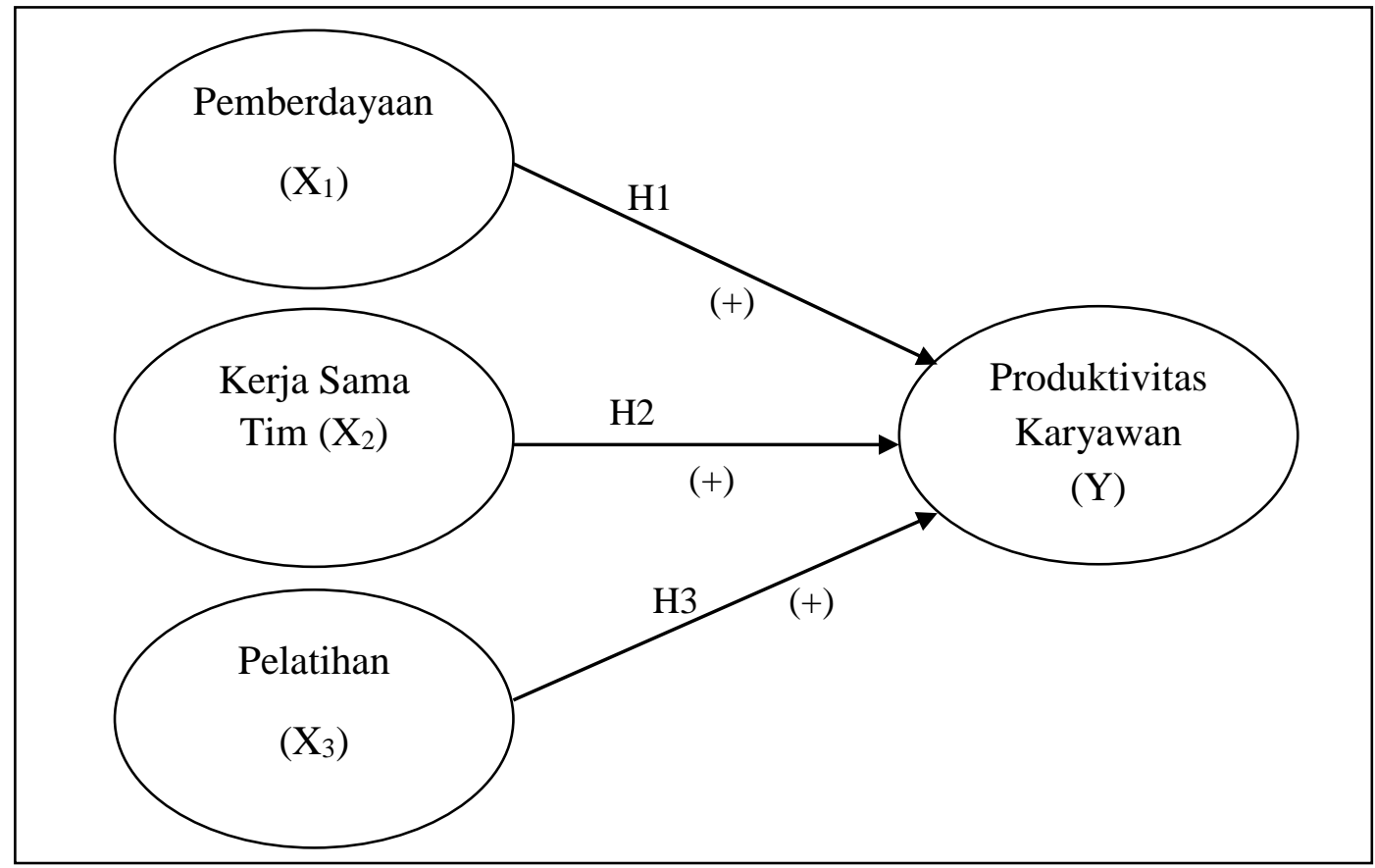

Sumber: pengembangan studi-studi empiris sebelumnya

\section{METODE}

Desain penelitian asosiatif menjelaskan pengaruh variabel bebas yaitu pemberdayaan $\left(\mathrm{X}_{1}\right)$, kerja sama tim $\left(\mathrm{X}_{2}\right)$ dan Pelatihan $\left(\mathrm{X}_{3}\right)$ terhadap variabel terikat produktivitas karyawan $(\mathrm{Y})$. Penelitian mengambil lokasi di perusahaan jasa pendukung pariwisata yaitu Unagi Spa Bali. Data kuantitatif berupa data jumlah karyawan serta skor jawaban responden dan data kualitatif berupa hasil wawancara mengenai gambaran umum perusahaan Unagi Spa Bali dan struktur organisasi Unagi Spa Bali.

Sumber primer diperoleh secara langsung dari Karyawan Unagi Spa Bali, sedangkan sumber sekunder berupa: jumlah karyawan, Laporan Operasional dan Keuangan, Masterlist Unagi, Organization Chart dan Orientation Program Unagi Spa Bali seta pengumpulan data melalui wawancara dan penyebaran kuesioner. 
Populasi menjadi sampel penelitian ini sebanyak 40 orang karyawan dengan teknik sampel jenuh.

Tabel 2. Populasi dan Sampel Unagi Spa Bali

\begin{tabular}{|c|c|c|}
\hline No. & Departemen & Banyaknya (orang) \\
\hline 1 & $H R D$ & 5 \\
\hline 2 & Administration and General & 4 \\
\hline 3 & Accounting & 2 \\
\hline 4 & Front Office & 4 \\
\hline 5 & House Keeping & 3 \\
\hline 6 & Therapist & 22 \\
\hline & Total & 40 \\
\hline
\end{tabular}

Sumber: HR Coordinator Unagi Spa Bali, 2017

Data diukur dengan skala linkert kepada karyawan Unagi Spa Bali melalui pernyataan dari indikator masing-masing variabel lalu diukur dengan rentang nilai 1 sampai 5. Instrumen penelitian yang digunakan telah diuji melalui uji reliabilitas. Kuesioner variabel pemberdayaan berisi 6 butir pernyataan dengan nilai Cronbach's Alpha sebesar 0,901 (Khan, 2007). Variabel kerja sama tim berisi 5 butir pernyataan dengan nilai Cronbach's Alpha sebesar 0,905 (Dewi, 2007). Variabel pelatihan berisi 5 butir pernyataan dengan nilai Cronbach's Alpha sebesar 0,916 (Schmidt, 2004) dan variabel produktivitas karyawan berisi 6 butir pernyataan dengan nilai Cronbach's Alpha sebesar 0,908 (Sutrisno, 2007). Keseluruhan kuesioner berada diatas nilai 0,6 berarti instrumen reliabel kemudian layak digunakan untuk penelitian.

Data penelitian kemudian diolah dengan menganalisis secara deskriptif serta inferensial. Analisis deskriptif dapat menghasilkan informasi distribusi skor rata-rata respon individu dan juga dilakukan uji hipotesis penelitian melalui metode regresi linier. Teknik regresi linear berganda didukung program SPSS 
versi 18.0 untuk menganalisis. Model regresi linear berganda dirumuskan sebagai berikut:

$$
\hat{\mathrm{Y}}=\mathrm{a}+\mathrm{b}_{1} \mathrm{X}_{1}+\mathrm{b}_{2} \mathrm{X}_{2}+\mathrm{b}_{3} \mathrm{X}_{3}+\mathrm{e}_{\mathrm{i}}
$$

Keterangan:

$\begin{array}{ll}\hat{\mathrm{Y}} & : \text { Produktivitas Karyawan } \\ \mathrm{X}_{1} & : \text { Pemberdayaan } \\ \mathrm{X}_{2} & : \text { Kerja sama tim } \\ \mathrm{X}_{3} & : \text { Pelatihan } \\ \mathrm{b}_{1} \mathrm{~b}_{2} \mathrm{~b}_{3} & : \text { koefisien regresi } \mathrm{X}_{1}, \mathrm{X}_{2}, \mathrm{X}_{3} \\ \mathrm{e}_{\mathrm{i}} & : \text { eror }\end{array}$

Hasil keluaran dari model regresi yang diciptakan juga dilengkapi dengan uji ketepatan model melalui uji statistik $\mathrm{F}$ dan uji determinasi $\mathrm{R}^{2}$ serta uji asumsi klasik kemudian hasil dari masing-masing keluaran SPSS tersebut diuji lewat ukuran kepercayaan $95 \%$ maupun $\alpha=5 \%=0,05$.

\section{HASIL DAN PEMBAHASAN}

\section{Gambaran Lokasi Penelitian}

Unagi Spa Bali merupakan sebuah perusahaan yang bergerak dalam bidang jasa pendukung pariwisata yakni SPA massage yang berlokasi di jalan Teuku Umar Barat No. 379 Denpasar, Bali. Unagi Spa Bali telah berdiri sejak bulan Desember Tahun 2015. Pada tanggal 14 Juli 2016 Unagi Spa Bali mengadakan kerjasama dengan PT. Kanaya Hospitality Sukses dalam hal pengelolaan SPA yang berada dalam bangunan seluas kurang lebih 20 are. Unagi Spa Bali termasuk sebagai perusahaan yang sedang berkembang Unagi Spa Bali memiliki target "To Be Local Champion Spa Industry in Bali within a Year”. 
I Made Adi Prabawa, Meningkatkan Produktivitas Karyawan Melalui...

Usaha dalam mencapai target tersebut salah satunya yaitu menjalin kerjasama dengan berbagai mitra kerja untuk dapat menpertahankan keberlangsungan perusahaan seperti meningkatkan penjualan serta jumlah kunjungan. Dalam mendukung keberhasilan usahanya, Unagi Spa Bali telah bekerjasama dengan Jaya Tour, Hotelier, Walk In, Red Apple, Aberu, Pro Bali, Varawedding, WOW, APA Tour, Groupon dan sebagainya. Hasilnya, Unagi Spa Bali dapat menguasai pangsa pasar wisatawan lokal dan asing terutama wisatawan group. Paket Spa yang ditawarkan juga beragam serta terjangkau mulai dari harga Rp 120.000,00 hingga Rp 550.000,00 dan juga rutin mengadakan promo melalui iklan di berbagai media.

Struktur organisasi yang digunakan di Unagi Spa Bali adalah struktur garis. Struktur organisasi garis adalah bentuk organisasi yang paling sederhana karena kekuasaan berada pada satu orang pimpinan, dimana pelimpahan kekuasaan yaitu tugas dan wewenang dilakukan secara vertikal dari atasan kepada bawahan, begitu pula bawahan juga bertanggung jawab secara vertikal kepada atasan. Adanya kejelasan sistem manajemen di dalam perusahaan membuat pekerjaan menjadi lebih jelas dan dapat dipertanggungjawabkan sehingga dapat menetapkan manajemen strategik terbaik dan tepat untuk keberlangsungan bisnis di Unagi Spa Bali.

Perusahaan Unagi Spa Bali dipilih menjadi lokasi penelitian sebab ditemukannya permasalahan mengenai produktivitas karyawan yang berfluktuatif berdasarkan data perusahaan tahun 2017 lantas diduga dipengaruhi oleh keadaan perusahaan seperti pemberdayaan, kerja sama tim dan pelatihan. Selain itu 
pemilihan lokasi juga didasari oleh ketersediaan data yang memadai dan mampu untuk diolah.

\section{Karakteristik Responden}

Dirangkum berdasarkan Tabel 3 mengambarkan responden didominasi berjenis kelamin perempuan sejumlah 32 orang atau 80 persen. Responden sebagian besar berusia antara 16-25 tahun yaitu sebanyak 20 orang atau sebesar 50 persen. Karyawan yang bekerja di perusahaan Unagi Spa Bali dominan bermasa kerja sekitar 1-2 tahun yaitu sebanyak 26 orang atau 65 persen.

Tabel 3. Karakteristik Responden

\begin{tabular}{ccccc}
\hline No. & Karakteristik & Klasifikasi & Jumlah (org) & Presentase (\%) \\
\hline 1 & Jenis Kelamin & Laki-laki & 8 & 20 \\
& & Perempuan & 32 & 80 \\
& & Jumlah & 40 & 100 \\
\hline 2 & Umur & $16-25$ & 20 & 50 \\
& (tahun) & $26-35$ & 15 & 37.5 \\
& & $36-45$ & 4 & 10 \\
& & $16-55$ & 40 & 2.5 \\
& & Jumlah & 5 & 100 \\
\hline 3 & Pendidikan & SMP & 24 & 12.5 \\
& & SMA/SMK & 1 & 60 \\
& & D1 & 1 & 2.5 \\
& & D2 & 6 & 2.5 \\
& & D3 & 3 & 15 \\
& & Sarjana (S1) & 40 & 7.5 \\
& & Jumlah & 14 & 100 \\
\hline 4 & Masa Kerja & 1 tahun & 26 & 35 \\
& & $1-2$ tahun & 40 & 65 \\
& & Jumlah & & 100 \\
\hline
\end{tabular}

Sumber: Hasil pengolahan data penelitian, 2017

Setelah dilakukan tabulasi hasil jawaban responden dilaporkan hasil penelitian sehingga dapat diinterpretasi dan selanjutnya nilai rata-rata skor setiap variabel dilaporkan dengan pengukuran nilai persepsi responden terhadap masingmasing variabel diukur melalui rata-rata skor yang dikategorikan menjadi lima 
I Made Adi Prabawa, Meningkatkan Produktivitas Karyawan Melalui...

bagian (Wirawan, 2014) yaitu: 1,00 - 1,80 (sangat rendah/sangat buruk) 1,81 2,61 (rendah/buruk) 2,61 - 3,40 (cukup tinggi/cukup baik) 3,41 - 4,20 (tinggi/baik) 4,21 - 5,00 (sangat tinggi/sangat baik).

\section{Rangkuman Interpretasi Variabel}

\section{Pemberdayaan}

Penjelasan variabel pemberdayaan pada Tabel 4 yang menunjukan nilai rata-rata skor melalui 6 butir pernyataan adalah 3,89. Nilai tersebut berarti pemberdayaan di Unagi Spa Bali tergolong baik. Kondisi pemberdayaan ini terlihat dari indikator keterlibatan sebesar 4,02. Skor tersebut terletak pada rentang 3,41 - 4,20 dalam kategori baik. Hal ini berarti secara keseluruhan responden setuju bahwa karyawan terlibat kerja untuk menyelesaikan pekerjaan dalam tim. Skor yang paling rendah adalah 3,72 yaitu pada indikator kepercayaan. Tabel 4. Deskripsi Jawaban Responden Variabel Pemberdayaan

\begin{tabular}{llccccccc}
\hline \multirow{2}{*}{ No. } & \multicolumn{3}{c}{ Indikator } & \multicolumn{3}{c}{ Jawaban Responden } & Rata-rata & \multirow{2}{*}{ Kategori } \\
\cline { 3 - 7 } & & STS & TS & N & S & SS & Skor & \\
\hline 1. & Keterlibatan & 0 & 2 & 9 & 15 & 14 & 4,02 & Baik \\
2. & Kepercayaan & 0 & 5 & 9 & 18 & 8 & 3,72 & Baik \\
3. & Kepercayaan diri & 0 & 6 & 4 & 15 & 15 & 3,97 & Baik \\
4. & Kredibilitas & 0 & 2 & 13 & 10 & 15 & 3,95 & Baik \\
5. & Akuntabilitas & 0 & 3 & 11 & 15 & 11 & 3,85 & Baik \\
6. & Komunikasi & 0 & 3 & 10 & 17 & 10 & 3,85 & Baik \\
\hline \multicolumn{7}{c}{ Total rata-rata pemberdayaan } \\
\hline
\end{tabular}

Sumber: Hasil pengolahan data penelitian, 2017

\section{Kerja Sama Tim}

Penjelasan variabel kerja sama tim pada Tabel 5 yang menunjukan nilai rata-rata skor melalui 5 butir pernyataan adalah 3,97. Nilai tersebut berarti kerja sama tim di Unagi Spa Bali tergolong baik. Kondisi kerja sama tim ini terlihat dari indikator bekerjasama sebesar 4,07. Skor tersebut terletak pada rentang 3,41 
- 4,20 dalam kategori baik. Hal ini berarti secara keseluruhan responden setuju bahwa setiap anggota tim dapat bekerjasama dengan baik dalam menyelesaikan pekerjaan-pekerjaan yang ditugaskan. Skor yang paling rendah adalah 3,90 yaitu pada indikator memberi dorongan.

Tabel 5. Deskripsi Jawaban Responden Variabel Kerja Sama Tim

\begin{tabular}{llccccccc}
\hline \multirow{2}{*}{ No. } & \multicolumn{6}{c}{ Indikator } & \multicolumn{9}{c}{ Jawaban Responden } & \multicolumn{2}{c}{ Rata-rata } & Kategori \\
\cline { 3 - 7 } & & STS & TS & N & S & SS & Skor & \\
\hline 1. & Bekerjasama & 0 & 6 & 1 & 17 & 16 & 4,07 & Baik \\
2. & Mengungkapkan harapan positif & 0 & 2 & 15 & 8 & 15 & 3,92 & Baik \\
3. & Menghargai masukan & 0 & 3 & 10 & 10 & 17 & 4,02 & Baik \\
4. & Memberi dorongan & 0 & 3 & 11 & 13 & 13 & 3,90 & Baik \\
5. & Membangun semangat kelompok & 0 & 5 & 4 & 18 & 13 & 3,97 & Baik \\
\hline \multicolumn{7}{c}{ Total rata-rata kerja sama tim } \\
\hline
\end{tabular}

Sumber: Hasil pengolahan data penelitian, 2017

\section{Pelatihan}

Penjelasan variabel pelatihan pada Tabel 6 yang menunjukan nilai rata-rata skor melalui 5 butir pernyataan adalah 3,86. Nilai tersebut berarti pelatihan di Unagi Spa Bali tergolong baik. Kondisi pelatihan ini terlihat dari indikator dukungan organisasi sebesar 4,10. Skor tersebut terletak pada rentang 3,41-4,20 dalam kategori baik. Hal ini berarti secara keseluruhan responden setuju bahwa adanya dukungan perusahaan telah menyediakan pelatihan untuk memenuhi kebutuhan kerja dalam mendukung peningkatan produktivitas. Skor yang terendah adalah 3,67 pada indikator perasaan terhadap pelatihan.

Tabel 6. Deskripsi Jawaban Responden Variabel Pelatihan

\begin{tabular}{llccccccc}
\hline \multirow{2}{*}{ No. } & \multicolumn{6}{c}{ Indikator } & \multicolumn{3}{c}{ Jawaban Responden } & Rata-rata & \multirow{2}{*}{ Kategori } \\
\cline { 3 - 7 } & & STS & TS & N & S & SS & Skor & \\
\hline 1. & Dukungan organisasi & 0 & 5 & 2 & 17 & 16 & 4,10 & Baik \\
2. & Perasaan tentang pelatihan & 0 & 4 & 13 & 15 & 8 & 3,67 & Baik \\
3. & Perasaan tentang pelatihan & 0 & 6 & 4 & 16 & 14 & 3,95 & Baik \\
4. & Kepuasan terhadap pelatihan & 0 & 2 & 11 & 15 & 12 & 3,92 & Baik \\
5. & Kepuasan terhadap pelatihan & 0 & 5 & 10 & 17 & 8 & 3,70 & Baik \\
\hline \multicolumn{6}{c}{ Total rata-rata pelatihan } \\
\hline
\end{tabular}

Sumber: Hasil pengolahan data penelitian, 2017 
I Made Adi Prabawa, Meningkatkan Produktivitas Karyawan Melalui...

\section{Produktivitas Karyawan}

Penjelasan variabel produktivitas karyawan pada Tabel 7 yang menunjukan nilai rata-rata skor melalui 6 butir pernyataan adalah 3,73. Nilai tersebut berarti produktivitas karyawan di Unagi Spa Bali tergolong tinggi. Kondisi produktivitas karyawan dapat dilihat dari indikator kemampuan sebesar 3,95. Skor tersebut terletak pada rentang 3,41 - 4,20 dalam kategori tinggi. Hal ini berarti secara keseluruhan responden setuju bahwa mereka memiliki kemampuan untuk mengerjakan pekerjaan sesuai dengan tugas. Skor yang paling rendah adalah 3,60 yaitu pada indikator pengembangan diri.

Tabel 7. Deskripsi Jawaban Responden Variabel Produktivitas Karyawan

\begin{tabular}{llccccccc}
\hline \multirow{2}{*}{ No. Indikator } & \multicolumn{5}{c}{ Jawaban Responden } & Rata-rata & \multirow{2}{*}{ Kategori } \\
\cline { 3 - 6 } & & STS & TS & N & S & SS & Skor & \\
\hline 1. & Kemampuan & 0 & 3 & 5 & 23 & 9 & 3,95 & Tinggi \\
2. & Meningkatkan hasil yang dicapai & 0 & 5 & 13 & 13 & 9 & 3,65 & Tinggi \\
3. & Semangat kerja & 0 & 4 & 5 & 23 & 8 & 3,87 & Tinggi \\
4. & Pengembangan diri & 0 & 5 & 10 & 21 & 6 & 3,60 & Tinggi \\
5. & Mutu & 0 & 5 & 8 & 21 & 6 & 3,70 & Tinggi \\
6. & Efisiensi & 0 & 2 & 14 & 20 & 4 & 3,65 & Tinggi \\
\hline \multicolumn{2}{c}{ Total rata-rata produktivitas karyawan } \\
\hline
\end{tabular}

Sumber: Hasil pengolahan data penelitian, 2017

\section{Hasil Analisis Linear Berganda}

Hasil rangkuman analisis regresi linier berganda Tabel 8 digunakan untuk pengujian hipotesis menyatakan bahwa persamaan yang diciptakan yaitu:

$$
\hat{Y}=-2,795+0,429 X_{1}+0,413 X_{2}+0,483 X_{3}+e_{i}
$$

Nilai pada kolom B melaporkan pemberdayaan sebesar 0,429 kerja sama tim sebesar 0,413 dan pelatihan 0,483 nilai tersebut mengarah pada pengaruh positif. Hal tersebut menyatakan bahwa naiknya nilai salah satu variabel maka 
semakin bertambah nilai tersebut terhadap produktivitas kerjanya. Kemudian keseluruhan variabel tersebut juga menunjukan nilai signifikansinya dibawah ukuran pengujian $\alpha=0,05$. Hal ini menyatakan pengaruh yang signifikan per variabel bebas kepada variabel terikatnya. Dapat diperjelas variabel pemberdayaan, kerja sama tim dan pelatihan secara parsial berpengaruh positif dan signifikan terhadap variabel terikat yaitu produktivitas karyawan.

Tabel 8. Analisis Regresi Linear Berganda

\begin{tabular}{lccrr}
\hline \multirow{2}{*}{ Model } & \multicolumn{2}{c}{ Regrs. } & $\mathrm{t}$ & \multirow{2}{*}{ Sig. } \\
\cline { 2 - 3 } & $\mathrm{B}$ & Std Er. & \\
\hline Pemberdayaan & 0,429 & 0,098 & 4,368 & 0,000 \\
$\quad$ Kerja Sama Tim & 0,413 & 0,114 & 3,610 & 0,001 \\
$\quad$ Pelatihan & 0,483 & 0,111 & 4,372 & 0,000 \\
\hline Const. & & & & $-2,792$ \\
R & & & & 0,822 \\
R Square & & & 0,676 \\
F Statistik & & & 25,057 \\
Signifikansi & & & 0,000 \\
\hline
\end{tabular}

Sumber: Hasil pengolahan data penelitian, 2017

Uji ketepatan model dirangkum pada nilai signifikansi F Statistik adalah 0,000 serta lebih kecil dari nilai $\alpha=0,05$ artinya, model regresi linear berganda tepat digunakan dalam menguji pengaruh variabel bebas yaitu pemberdayaan, kerja sama tim dan Pelatihan terhadap variabel terikat yaitu produktivitas karyawan. Hasil Uji F yang signifikan selanjutnya merupakan syarat untuk dapat dapat meninterpretasikan seberapa konstribusi variabel bebas terhadap variabel terikat.

Penjelasan nilai $\mathrm{R}^{2}$ dapat digunakan untuk mengukur seberapa besar presentase hubungan produktivitas karyawan dapat ditingkatkan dengan variabel pemberdayaan, kerja sama tim dan pelatihan. Nilai koefisien $R^{2}$ sebesar 0,676 memiliki arti bahwa pemberdayaan, kerja sama tim dan pelatihan dapat 
I Made Adi Prabawa, Meningkatkan Produktivitas Karyawan Melalui...

menjelaskan variabel produktivitas karyawan sebesar 67,6 persen dan 32,4 persen sisanya tidak dimuat di model.

\section{Hasil Pengujian Asumsi Klasik}

Tabel 9 melaporkan Nilai Kmgrv-Smrnv sebesar 0,112 dan nilai Asy.Sig 0,2 lebih besar 0,05 ini berarti residual dari persamaan regresi dalam penelitian ini terdistribusi secara normal. Nilai Kolmogorov-Smirnov merupakan koefisien yang digunakan untuk mengukur kenormalan distribusi data.

Tabel 9. Hasil Uji Normalitas

\begin{tabular}{ll} 
& $\begin{array}{l}\text { Residu } \\
\text { Unstand. }\end{array}$ \\
\hline$N$ & 40 \\
Kmgrv-Smrnv Z & 0,112 \\
Asy.Sig.(2-tailed) & 0,2
\end{tabular}

Sumber: Hasil pengolahan data penelitian, 2017

Tabel 10 melaporkan keseluruhan variabel pemberdayaan, kerja sama tim dan pelatihan menunjukan nilai $\mathrm{VIF}<10$ serta nilai tolerance $>0,1$ artinya hasil regresi bebas multikolinearitas.

Tabel 10. Hasil Uji Multikolinearitas

\begin{tabular}{lcc}
\hline \multicolumn{1}{c}{ Variabel } & Tolerance & VIF \\
\hline Pemberdayaan & 0,921 & 1,086 \\
Kerja Sama Tim & 0,929 & 1,076 \\
Pelatihan & 0,957 & 1,045
\end{tabular}

Sumber: Hasil pengolahan data penelitian, 2017

Tabel 11 melaporkan keseluruhan nilai Sig. variabel pemberdayaan, kerja sama tim dan pelatihan lebih besar 0,05. Hal ini berarti memenuhi syarat homoskedastisitas dan bebas gejala heteroskedastisitas. 
Tabel 11. Hasil Uji Heteroskedastisitas

\begin{tabular}{lcc}
\hline \multicolumn{1}{c}{ Variabel } & $\mathrm{t}_{\text {hitung }}$ & Sig. \\
\hline Pemberdayaan & $-0,130$ & 0,897 \\
\hline Kerja Sama Tim & $-1,818$ & 0,077 \\
\hline Pelatihan & $-0,344$ & 0,733 \\
\hline
\end{tabular}

Sumber: Hasil pengolahan data penelitian, 2017

\section{Pembahasan Hasil Penelitian}

\section{Pengaruh Pemberdayaan Terhadap Produktivitas Karyawan}

Pemberdayaan memperoleh rata-rata skor 3,89 yang diukur dengan 6 pernyataan kepada responden. Dapat dinyatakan karyawan di Unagi Spa Bali memperoleh pemberdayaan yang tergolong dalam kategori baik. Hal tersebut mendukung hipotesis pertama (H1) yakni pemberdayaan berpengaruh positif terhadap produktivitas karyawan di Unagi Spa Bali. Chang (2008) melaporkan hasil dan menemukan jika pemberdayaan mengarah ke hasil positif organisasi, seperti tanggung jawab dan motivasi dalam pekerjaan rutin ditingkat karyawan, meningkatkan kepuasan kerja, kualitas layanan yang lebih baik, loyalitas karyawan yang lebih tinggi, dan memaksimalkan produktivitas. Karacoc (2009) juga menyebutkan dengan mengadopsi strategi pemberdayaan, diyakini bahwa karyawan dapat merasakan diri mereka layak, sehingga berdampak pada produktivitas dan kualitas kerjanya. Chehrazi dan Shafizadeh (2016) melaporkan hasil yang positif sekaligus signifikan dan menyatakan terdapat hubungan erat antara pemberdayaan karyawan dengan kepuasan kerja, sehingga meningkatkan produktivitas. Meyerson dan Dewettinck (2012) juga menemukan bahwa pemberdayaan memiliki efek positif sekaligus signifikan pada produktivitas karyawan. 
I Made Adi Prabawa, Meningkatkan Produktivitas Karyawan Melalui...

Hasil serupa meyakinkan Teori $\mathrm{Z}$ pengembangan Widodo (2015) menyatakan Teori Z sangat relevan dengan pemberdayaan karena menekankan perlunya berbagai wewenang pengambilan keputusan dan perlunya mengurangi rintangan-rintangan akibat perbedaan status artifisial antar karyawan, anggota dan manajer, dan menekankan perlunya komunikasi yang lebih baik serta tanggungjawab pribadi yang lebih besar atas hasil kerja, juga pengakuan yang lebih besar atas konstribusi tiap individu kepada tim. Jadi Teori $\mathrm{Z}$ ini mendukung penelitian bahwa pemberdayaan berpengaruh positif dan signifikan terhadap produktivitas.

\section{Pengaruh Kerja Sama Tim Terhadap Produktivitas Karyawan}

Kerja sama tim memperoleh rata-rata skor 3,97 yang diukur dengan 5 pernyataan. Dapat dinyatakan karyawan di Unagi Spa Bali melakukan kerja sama tim yang tergolong dalam kategori baik. Hal tersebut mendukung hipotesis kedua (H2) yakni kerja sama tim berpengaruh positif terhadap produktivitas karyawan di Unagi Spa Bali. Mayoritas organisasi yang berfokus pada kerja sama tim dalam upaya untuk mencapai target, akan meningkatkan produktivitas. Penelitian Cohen dan Bailey (2009) melaporkan yakni kerja sama tim berpengaruh positif serta signifikan terhadap produktivitas dan kinerja organisasi. Gallie et al., (dalam Hanaysha, 2014) melaporkan jika organisasi yang lebih menekankan pada kerja sama tim dapat menikmati hasil yang menguntungkan seperti meningkatkan kinerja karyawan, produktivitas tinggi dan pengembangan keterampilan dalam menyelesaikan pekerjaan. Hanaysha (2014) melaporkan hasil kerja sama tim yang positif dan signifikan terhadap produktivitas karyawan sekaligus menegaskan 
bahwa kerja sama tim memperkaya produktivitas melalui peningkatan ruang lingkup pengetahuan, keterampilan, dan kemampuan karyawan berbagi dengan karyawan lainnya. Penelitian yang dikemukakan oleh Agarwal (2016) melaporkan kerja sama tim mengarah positif dan signifikan serta merekomendasikan untuk mengadopsi kerja sama tim dalam meningkatkan produktivitas organisasi dalam tingkat yang lebih luas.

\section{Pengaruh Pelatihan Terhadap Produktivitas Karyawan}

Pelatihan memperoleh rata-rata skor 3,86 diukur dengan 5 pernyataan. Dapat dinyatakan karyawan di Unagi Spa Bali memperoleh pelatihan yang tergolong dalam kategori baik. Hal tersebut mendukung hipotesis ketiga (H3) yakni pelatihan berpengaruh positif terhadap produktivitas di Unagi Spa Bali. Hasil penelitian Colombo dan Stanca (2008) melaporkan pelatihan berpengaruh ke arah positif dan signifikan sekaligus menguatkan penjelasan tentang pelatihan sebagai alat utama dan kuat untuk berhasil mencapai tujuan organisasi dan meningkatkan produktivitas karyawan. Appiah (2010) menunjukan pengaruh pelatihan yang positif dan signifikan terhadap produktivitas sekaligus menegaskan bahwa program pelatihan yang dirancang untuk memberikan manfaat yang lebih besar bagi karyawan dan organisasi itu sendiri, dengan melalui berbagi pengetahuan, keterampilan, dan kompetensi dapat meningkatan produktivitas karyawan. Sabir et al., (2014) menemukan bahwa pelatihan dapat memungkinkan karyawan untuk memaksimalkan tingkat produktivitas dalam skala pekerjaan yang lebih besar. Produktivitas karyawan menjadi lebih efisien jika menerima pelatihan yang efektif dan menyebutak hasil yang positif serta signifikan (Elnaga 
I Made Adi Prabawa, Meningkatkan Produktivitas Karyawan Melalui...

dan Imran, 2013). Asava (2013) juga menemukan bahwa pelatihan mengarah ke hasil yang positif yang signifikan melalui dimensi-dimensi pelatihan yaitu pengetahuan, sikap, keterampilan dan kapasitas terhadap produktivas.

\section{SIMPULAN DAN SARAN}

Berlandaskan pada hasil dan pembahasan penelitian dapat disimpulan pemberdayaan memiliki pengaruh positif dan signifikan terhadap produktivitas karyawan, kerja sama tim memiliki pengaruh positif dan signifikan terhadap produktivitas karyawan, dan pelatihan memiliki pengaruh positif dan signifikan terhadap produktivitas karyawan.

Pengajuan saran mengacu pada hasil dan pembahasan penelitian berupa meningkatkan pemberdayaan terhadap karyawan seperti kepercayaan manajemen atau atasan terhadap kompetensi yang dimiliki karyawannya untuk menyelesaikan pekerjaan yang ditugaskan harus ditingkatkan. Karyawan merasa dipercaya apabila lebih dilibatkan dalam pengambilan keputusan bahkan merekomendasikan cara kerja baru agar dapat lebih produktif. Meningkatkan kerja sama tim dapat dilakukan dengan membentuk tim yang baik seperti perlunya meningkatkan kedekatan dan ikatan antar karyawan sehingga tercipta rasa tolong menolong dan saling mendukung dalam tim kerja untuk mencapai tujuan perusahaan. Perusahaan juga harus mampu menyusun dan meningkatkan pelatihan yang diberikan untuk memenuhi, meningkatkan dan mengembangkan kemampuan bekerja karyawan seperti mengatur kembali jadwal pelatihan secara periodik dan menambah jenis pelatihan yang sesuai dengan kebutuhan kerja saat ini, mengingat persaingan yang 
semakin tinggi. Penelitian selanjutnya dapat mencangkup ruang lingkup sektor jasa yang lebih luas dan mungkin menambah variabel moderating seperti tingkat pendidikan, ukuran organisasi, aspek penghargaan dan aspek lainnya. Hal tersebut memungkinkan untuk mengidentifikasi aspek kunci lain yang harus dipertimbangkan dalam merancang strategi sumber daya manusia yang efektif untuk meningkatkan produktivitas karyawan dan daya saing perusahaan.

\section{REFERENSI}

Agarwal, S. (2016). Impact Teamwork on Organizational Productivity in Some Selected Basic Schools in the Accra Metropolitan Assembly. European Journal of Business, Economics and Accountancy, 4 (6), 40-52.

Appiah, B. (2010). "Impact of Training on employee performance" (tesis). Ghana: Ashesi University.

Asava, M.M. (2013). "Influences trainin on employees productivity in the processing sector" (disertasi). Kenya: Nairobi University.

Athar, R., and Shah, F.M. (2015). Impact of Training on Employees Performance (Baking Sector Karachi). IOSR Journal of Business and Management 17 (11), 58-67.

Benrazavi, S., and Silong, A.D. (2013). Employee's Job and Influence on Willingness to work in team. Journal of Management Policy and Practice, $14(1), 127-140$.

Chang, L., and Liu, C.H. (2008). Employee empowerment, innovative behavior and job productivity of public health nurses: A cross-sectional questionnaire survey. International Journal of Nursing Studies, 45 (10), $1442-1448$.

Chen, Y., \& Tjosvold, D. (2008). Collectivist value for productive teamwork between Korean and Chinese employees. Working Paper Series. Hong Kong: Lingnan University.

Chehrazi and Shafizadeh, R. (2016). The Relationship of Empowerment and Job Satisfaction Productivity of Employees of Education System in Ahwaz. International Journal of Learning \& Development, 6 (1), 11-24. 
Cohen, G., and Bailey, E. (2009). Centre for Effective Organization Teams. Journal of Management, 23 (3), 239-290.

Colombo, and Stanca, Luca. (2008). The Impact of Trainin for Productivities: Evidence a Large Panel of Firm. Working Paper Series. Departemen of Economic University of Milan - Biocca.

Dewi, Sandara. (2007). Cara Membangun Team Impian.

Bandung: Progressio.

Elnaga, Amir Abou., and Imran, Amen. (2014). The Impact of Employees Empowerment on Job Satisfactions. Theoretical Study. American Journal of Research Communication, 2 (1), 13-26.

Ferreira and Du Plessis. (2009). Effect Online Social Networking Employees Productvity. Peer Review Article, 11 (1), 1-16.

Ghozali, Imam. (2012). Aplikasi Analisis Multivariate Dengan Program SPSS 19. Edisi Kelima. Semarang: BP Universitas Diponegoro.

Hanaysha, Jalal. (2016). Testing the Effect of Employees Empowerment Teamwork, Employees Training on Employees Productivity in Higher Education. International Journal of Learning and Development, 6 (1), 164-178.

Hanif, F., and Abdullah. (2013). Impact of training on employees development and performance in hotel industries. Journal of Business Studies Quarterly, 4 (4), 68-82.

Heredero, P.S., Haider and A. García. (2015). Relational Coordination as Indicator Teamwork Quality: Potential Applications the Success eLearning at Universities. iJET, 10 (2), 4-8.

Jacquiline. (2014). Employees empowermen and jobs satisfied. Research Journal of Human Resource, 2 (2), 1-12.

Jiang, Xin. (2010). How to raise motivation peoples for working on team. International Journal of business and Management, 5 (10), 226-238.

Karakoc, Nihat. (2009). Employees Empowermen and Differentiations in Company: A Literature Review and Research Agenda. Enterprise Risk Management, 1 (2), 1-12

Khan. (2007). Keys of being a leader for company empowerment. International Journal for Quality and Participation, 2 (3), p: 15-17. 
Kien. (2012). Factors affectin the fluctuations labours productivity in the construction projects. (tesis). Vietnam: University of Economics, Ho Chi Minh City.

Manzoor, S. R., Ulah, H., Husain, M., and Ahmad, Z. M. (2011). Effects of teamworks for employees performance. International Journal of Learning and Development, 1 (1), 112-128.

Men. (2010). Measurin the impacts of leadership styles and employees empowermen on organizational reputation. Ketchum Excellent in Public Relations Research Award.

Meyerson, G., and Dewettinck. (2012). Effect of empowermen on employee performances. Advanced Research in Economic and Management Sciences, 2 (5), 42-48.

Mokhtar., Nooreha., Mustapha., and Mazilan. (2011). Value based total performances excellence model: Baseline assessment criteria guidelines for organisations. Institute Islamic Understanding Malaysia, linebreak Kuala Lumpur.

Polyzos, S. (2005). Labor Productivity of the Agricultural Sector in Greece: Determinants Factor and Interegional Differecation. Journal of Economic Management, 11 (12), 209-226.

Priansa, D.J. (2014). Perencanaan dan Pengembangan SDM. Edisi Pertama. Bandung: Alfabeta.

Sabir., Akhtar., Bukhari., Jwaria., and Ahmed. (2014). Impact of training on productivity of employees: A Case study of electricity supply company in Pakistan. International Review of Management and Business Research, 3 (2), 595-606.

Saifullah, N., Alam, M., Zafar, M. W., and Humayon, A. A. (2015). Job satisfaction: A Contest between human and organizational behaviors. International Journal of Economic Research, 6 (1), 46-53.

Schmidt, Steven. (2004). "Survey of job training and job satisfaction" (survey). Greenville: University of East Carolina

Seppala, Emma. (2015). Positive Teams for more Productive. Harvard Business Review. $\quad$ https://hbr.org/2015/03/positive-teams-are-more-productive (diunduh tanggal 18 Mei 2017)

Singh, R. (2012). Impacts of Trainin Practices on Employees Productivities: A Comparatif Studies. Interscience ManagementReview (IMR), 2 (2), 89-95. 
Sultana., Sobia., Kamran., and Nasir. (2012). Impact of training on employees performances: A Study of telecommunications sector in Pakistan. Interdisciplinary Journal of Contemporary Research in Business, 4 (6), 646-661.

Sutrisno, Edy. (2009). Manajemen Sumber Daya Manusia. Edisi Pertama. Jakarta: Kencana.

Tyson, Shaun. (2006). Essential of Human Resouce Management. $3^{\text {rd }}$ Edition. United Kingdom: Elsevier Ltd.

Unagi Spa Bali. 2017. Data Perusahaan 2017.

Vrat, P., Sardana, G. D., and Sahay, B. S. (2009). Productivities measurements onb usiness excellent. Alpha Science International.

Widodo, S. (2015). Manajemen Pengembangan Sumber Daya Manusia. Edisi Pertama. Yogyakarta: Pustaka Pelajar.

Wirawan, N. (2014). Statistik 2 Statistik Inferensial untuk Ekonomi dan Bisnis. Denpasar: Keraras Emas.

NB:

- HEADER FORMAT LIHAT PEDOMAN PENULISAN PADA WEB FE.UNUD.AC.ID (FONT TNR 11pt)

- HALAMAN FORMAT TNR 11pt PADA OJOK KANAN BAWAH

- JUMALH ARTIKEL 25-30 HALAMAN DILUAR REFERENSI

DEAR EDITOR:

REVISI NB:

1. HEADER FORMAT SUDAH SAYA SESUAIKAN DENGAN PEDOMAN SESUAI YANG TERTERA PADA WEB FE.UNUD.AC.ID

2. FORMAT HALAMAN SUDAH SAYA UBAH SESUAI ARAHAN DIATAS

3. TAMBAHAN PADA POIN GAMBARAN LOKASI PENELITIAN DAN PENJELASAN-PENJELASAN DIINTERPRETASI SENDIRI SESUAI HASIL PENELITIAN DAN SAYA BERANI MENJAMIN TIDAK ADA PLAGIARISME YANG BERARTI. BAGIAN TERAKHIR $=$ SIMPULAN DAN SARAN BERADA PADA HALAMAN 25 SEHARUSNYA SUDAH MEMENUHI SYARAT. TERIMAKASIH (: 